\title{
Formation pathway of AEI zeolites as a basis for a streamlined synthesis
}

Nao Tsunoji, ${ }^{* \dagger}$ Daigo Shimono, ${ }^{\dagger}$ Kazuyoshi Tsuchiya,$^{\dagger}$ Masahiro Sadakane,,$^{\dagger}$ and Tsuneji Sano ${ }^{\dagger}{ }^{\dagger}$

${ }^{\dagger}$ Graduate School of Engineering, Department of Applied Chemistry, Hiroshima University, 1-4-1

Kagamiyama, Higashi-Hiroshima 739-8527, Japan

\section{Corresponding author}

*Corresponding authors: Nao Tsunoji, tel.: +81-82-424-7606, e-mail: tnao7373@hiroshima-u.ac.jp; Tsuneji

Sano tel.: +81-82-424-7607, e-mail: tsano@hiroshima-u.ac.jp 
Table S1 Synthesis conditions of AEI zeolites using starting gels containing DMDMP and seed crystal ${ }^{\mathrm{a}}$

\begin{tabular}{|c|c|c|c|c|c|c|c|}
\hline \multirow{2}{*}{$\begin{array}{l}\text { Entry } \\
\text { (no. in Table 1) }\end{array}$} & \multirow{2}{*}{$\begin{array}{c}\text { Starting } \\
\text { materials }\end{array}$} & \multicolumn{4}{|c|}{ Gel composition } & \multicolumn{2}{|c|}{ Product } \\
\hline & & $\mathrm{OSDA} / \mathrm{SiO}_{2}$ & $\mathrm{Si} / \mathrm{Al}$ & $\mathrm{H}_{2} \mathrm{O} / \mathrm{SiO}_{2}$ & $\mathrm{NaOH} / \mathrm{SiO}_{2}$ & Phase & Yield [\%] \\
\hline $1(1)$ & $\mathrm{HSY}^{\mathrm{b}}$ & 0.2 & 19 & 5 & 0.1 & AEI & 63 \\
\hline 2 & HSY & 0.2 & 19 & 5 & 0.3 & FAU, AEI & 27 \\
\hline 3 & HSY & 0.2 & 19 & 5 & 0.45 & GME, AEI & 29 \\
\hline 4 & HSY & 0.2 & 19 & 5 & 0.6 & GME, ANA & 12 \\
\hline 5 & HSY & 0.2 & 19 & 10 & 0.1 & FAU & 76 \\
\hline 6 & $\mathrm{LSY}+\mathrm{Si}^{\mathrm{c}}$ & 0.17 & 30 & 10 & 0.1 & FAU & 60 \\
\hline 7 & $\mathrm{LSY}+\mathrm{Si}$ & 0.17 & 30 & 10 & 0.3 & Amorphous & 20 \\
\hline $8(4)$ & $\mathrm{LSY}+\mathrm{Si}$ & 0.17 & 30 & 10 & 0.45 & AEI & 27 \\
\hline 9 & $\mathrm{LSY}+\mathrm{Si}$ & 0.17 & 30 & 10 & 0.6 & GME, AEI & 7 \\
\hline 10 & $\mathrm{LSY}+\mathrm{Si}$ & 0.17 & 30 & 5 & 0.45 & AEI, GME & 25 \\
\hline 11 & $\mathrm{LSY}+\mathrm{Si}$ & 0.17 & 30 & 25 & 0.45 & FAU, Amorphous & 20 \\
\hline 12 & $\mathrm{SGP}^{\mathrm{d}}$ & 0.2 & 20 & 10 & 0.1 & Amorphous & 27 \\
\hline 13 & SGP & 0.2 & 20 & 10 & 0.3 & Amorphous & 16 \\
\hline $14(7)$ & SGP & 0.2 & 20 & 10 & 0.45 & AEI & 33 \\
\hline 15 & SGP & 0.2 & 20 & 10 & 0.6 & GME, AEI & 10 \\
\hline 16 & SGP & 0.2 & 20 & 5 & 0.45 & AEI & 22 \\
\hline 17 & SGP & 0.2 & 20 & 25 & 0.45 & Amorphous & 16 \\
\hline 18 & $\mathrm{CGP}^{\mathrm{e}}$ & 0.2 & 20 & 10 & 0.1 & Amorphous & 54 \\
\hline 19 & CGP & 0.2 & 20 & 10 & 0.3 & Amorphous & 21 \\
\hline $20(10)$ & CGP & 0.2 & 20 & 10 & 0.45 & AEI & 31 \\
\hline 21 & CGP & 0.2 & 20 & 10 & 0.6 & Amorphous & 16 \\
\hline 22 & CGP & 0.2 & 20 & 5 & 0.45 & AEI & 15 \\
\hline 23 & CGP & 0.2 & 20 & 25 & 0.45 & Amorphous & 17 \\
\hline
\end{tabular}

a Synthesis condition: $\mathrm{OSDA}=N, N$-Dimethyl-3,5,-dimethylpiperidinium hydroxide, Temperature $=150{ }^{\circ} \mathrm{C}$, Synthesis time $=3$ $\mathrm{d}$, Seed $=2 \mathrm{wt} \%($ AEI zeolite, $\mathrm{Si} / \mathrm{Al}=10) .{ }^{\mathrm{b}}$ Dealuminated FAU zeolite $(\mathrm{Si} / \mathrm{Al}=19) .{ }^{\mathrm{c}}$ Dealuminated FAU zeolite $(\mathrm{Si} / \mathrm{Al}=5.3)$ and colloidal silica (SI-30). ${ }^{\mathrm{d}}$ Amorphous gel prepared by stepwise preparation method using the first gel with Si/Al ratio of 5, $\mathrm{H}_{2} \mathrm{O} / \mathrm{SiO}_{2}$ ratio of 15 and $\mathrm{NaOH} / \mathrm{SiO}_{2}$ ratio of $0.4-2.4$. The final gel composition was fixed by adding the additional silica source (SI-30) and OSDA. ${ }^{\mathrm{e}}$ Conventional amorphous gel prepared by mixing all starting components in one-step. 
Table S2 Synthesis conditions of AEI zeolites using starting gels containing DEDMP and seed crystal ${ }^{\text {a }}$

\begin{tabular}{|c|c|c|c|c|c|c|c|}
\hline \multirow{2}{*}{$\begin{array}{l}\text { Entry } \\
\text { (no. in Table 1) }\end{array}$} & \multirow{2}{*}{$\begin{array}{l}\text { Starting } \\
\text { materials }\end{array}$} & \multicolumn{4}{|c|}{ Gel composition } & \multicolumn{2}{|c|}{ Product } \\
\hline & & $\mathrm{OSDA} / \mathrm{SiO}_{2}$ & $\mathrm{Si} / \mathrm{Al}$ & $\mathrm{H}_{2} \mathrm{O} / \mathrm{SiO}_{2}$ & $\mathrm{NaOH} / \mathrm{SiO}_{2}$ & Phase & Yield [\%] \\
\hline $24(2)$ & $\mathrm{HSY}^{\mathrm{b}}$ & 0.2 & 19 & 5 & 0.1 & AEI & 45 \\
\hline 25 & HSY & 0.2 & 19 & 5 & 0.45 & AEI & 51 \\
\hline 26 & HSY & 0.2 & 19 & 5 & 0.6 & AEI, GME & 22 \\
\hline 27 & HSY & 0.2 & 19 & 5 & 0.8 & ANA & 10 \\
\hline 28 & $\mathrm{LSY}+\mathrm{Si}^{\mathrm{c}}$ & 0.17 & 20 & 25 & 0.1 & FAU & 40 \\
\hline 29 & $\mathrm{LSY}+\mathrm{Si}$ & 0.17 & 20 & 25 & 0.45 & FAU & 16 \\
\hline $30(5)$ & $\mathrm{LSY}+\mathrm{Si}$ & 0.17 & 20 & 25 & 0.6 & AEI & 46 \\
\hline 31 & $\mathrm{LSY}+\mathrm{Si}$ & 0.17 & 20 & 25 & 0.8 & ANA, AEI & 26 \\
\hline 32 & $\mathrm{SGP}^{\mathrm{d}}$ & 0.2 & 10 & 10 & 0.1 & Amorphous & 38 \\
\hline $33(8)$ & SGP & 0.2 & 10 & 10 & 0.45 & AEI & 20 \\
\hline 34 & SGP & 0.2 & 10 & 10 & 0.6 & AEI, GME & 6 \\
\hline 35 & SGP & 0.2 & 10 & 10 & 0.8 & ANA & 8 \\
\hline 36 & $\mathrm{CGP}^{\mathrm{e}}$ & 0.2 & 10 & 10 & 0.1 & Amorphous & 48 \\
\hline $37(11)$ & CGP & 0.2 & 10 & 10 & 0.45 & Amorphous & 26 \\
\hline 38 & CGP & 0.2 & 10 & 10 & 0.6 & AEI, GME & 22 \\
\hline 39 & CGP & 0.2 & 10 & 10 & 0.8 & AEI, ANA & 23 \\
\hline
\end{tabular}

a Synthesis condition: $\mathrm{OSDA}=N, N$-Diethyl-2,6,-dimethylpiperidinium hydroxide, Temperature $=150{ }^{\circ} \mathrm{C}$, Synthesis time $=3 \mathrm{~d}$, Seed $=2 \mathrm{wt} \%(\mathrm{AEI}$ zeolite, $\mathrm{Si} / \mathrm{Al}=10) .{ }^{\mathrm{b}}$ Dealuminated FAU zeolite $(\mathrm{Si} / \mathrm{Al}=19) .{ }^{\mathrm{c}}$ Dealuminated FAU zeolite $(\mathrm{Si} / \mathrm{Al}=5.3)$ and colloidal silica (SI-30). ${ }^{\mathrm{d}}$ Amorphous gel prepared by stepwise preparation method using the first gel with Si/Al ratio of 5, $\mathrm{H}_{2} \mathrm{O} / \mathrm{SiO}_{2}$ ratio of 15 and $\mathrm{NaOH} / \mathrm{SiO}_{2}$ ratio of $0.4-2.4$. Amorphous gel prepared by stepwise preparation method using the first gel with $\mathrm{Si} / \mathrm{Al}$ ratio of $5, \mathrm{H}_{2} \mathrm{O} / \mathrm{SiO}_{2}$ ratio of 15 and $\mathrm{NaOH} / \mathrm{SiO}_{2}$ ratio of 0.4-2.4. The final gel composition was fixed by adding the additional silica source (SI-30) and OSDA. ${ }^{\mathrm{e}}$ Conventional amorphous gel prepared by mixing all starting components in one-step 
Table S3 Synthesis conditions of AEI zeolites using starting gels containing TEP and seed crystal ${ }^{\mathrm{a}}$

\begin{tabular}{|c|c|c|c|c|c|c|c|c|}
\hline \multirow{2}{*}{$\begin{array}{l}\text { Entry } \\
\text { (no. in Table 1) }\end{array}$} & \multirow{2}{*}{$\begin{array}{l}\text { Starting } \\
\text { materials }\end{array}$} & \multicolumn{4}{|c|}{ Gel composition } & \multirow{2}{*}{$\begin{array}{l}\text { Time } \\
\text { [d] }\end{array}$} & \multicolumn{2}{|c|}{ Product } \\
\hline & & $\mathrm{OSDA} / \mathrm{SiO}_{2}$ & $\mathrm{Si} / \mathrm{Al}$ & $\mathrm{H}_{2} \mathrm{O} / \mathrm{SiO}_{2}$ & $\mathrm{NaOH} / \mathrm{SiO}_{2}$ & & Phase & Yield [\%] \\
\hline $40(3)$ & $\mathrm{HSY}^{\mathrm{b}}$ & 0.2 & 19 & 5 & 0.1 & 7 & AEI & 59 \\
\hline 41 & HSY & 0.2 & 19 & 5 & 0.45 & 7 & GME, CHA & 20 \\
\hline 42 & HSY & 0.2 & 19 & 5 & 0.6 & 7 & GME, ANA & 22 \\
\hline 43 & HSY & 0.2 & 19 & 5 & 0.8 & 7 & ANA & 10 \\
\hline 44 & $\mathrm{LSY}+\mathrm{Si}^{\mathrm{c}}$ & 0.17 & 20 & 25 & 0.1 & 3 & FAU & 22 \\
\hline 45 & $\mathrm{LSY}+\mathrm{Si}$ & 0.17 & 20 & 25 & 0.45 & 3 & GME, CHA & 14 \\
\hline $46(6)$ & $\mathrm{LSY}+\mathrm{Si}$ & 0.17 & 20 & 25 & 0.6 & 3 & GME, CHA & 10 \\
\hline 47 & $\mathrm{LSY}+\mathrm{Si}$ & 0.17 & 20 & 25 & 0.8 & 3 & ANA & 36 \\
\hline 48 & $\mathrm{SGP}^{\mathrm{d}}$ & 0.2 & 10 & 10 & 0.1 & 3 & Amorphous & 38 \\
\hline $49(9)$ & SGP & 0.2 & 10 & 10 & 0.45 & 3 & Amorphous & 16 \\
\hline 50 & SGP & 0.2 & 10 & 10 & 0.6 & 3 & GME, CHA & 15 \\
\hline 51 & SGP & 0.2 & 10 & 10 & 0.8 & 3 & ANA & 7 \\
\hline 52 & $\mathrm{CGP}^{\mathrm{e}}$ & 0.2 & 10 & 10 & 0.1 & 3 & Amorphous & 29 \\
\hline $53(12)$ & CGP & 0.2 & 10 & 10 & 0.45 & 3 & Amorphous & 23 \\
\hline 54 & CGP & 0.2 & 10 & 10 & 0.6 & 3 & GME, CHA & 15 \\
\hline 55 & CGP & 0.2 & 10 & 10 & 0.8 & 3 & ANA & 7 \\
\hline
\end{tabular}

${ }^{a}$ Synthesis condition: $\mathrm{OSDA}=$ Tetraethylphosphonium hydroxide, Temperature $=150{ }^{\circ} \mathrm{C}, \mathrm{Seed}=2 \mathrm{wt} \%(\mathrm{AEI}$ zeolite, $\mathrm{Si} / \mathrm{Al}=10)$.

${ }^{\mathrm{b}}$ Dealuminated FAU zeolite $(\mathrm{Si} / \mathrm{Al}=19) .{ }^{\mathrm{c}}$ Dealuminated FAU zeolite $(\mathrm{Si} / \mathrm{Al}=5.3)$ and colloidal silica $(\mathrm{SI}-30) .{ }^{\mathrm{d}}$ Amorphous gel prepared by stepwise preparation method using the first gel with $\mathrm{Si} / \mathrm{Al}$ ratio of $5, \mathrm{H}_{2} \mathrm{O} / \mathrm{SiO}_{2}$ ratio of 15 and $\mathrm{NaOH} / \mathrm{SiO}_{2} \mathrm{ratio}$ of 0.4-2.4. Amorphous gel prepared by stepwise preparation method using the first gel with $\mathrm{Si} / \mathrm{Al}$ ratio of $5, \mathrm{H}_{2} \mathrm{O} / \mathrm{SiO}_{2}$ ratio of 15 and $\mathrm{NaOH} / \mathrm{SiO}_{2}$ ratio of $0.4-2.4$. The final gel composition was fixed by adding the additional silica source (SI-30) and OSDA. ${ }^{\mathrm{e}}$

Conventional amorphous gel prepared by mixing all starting components in one-step 

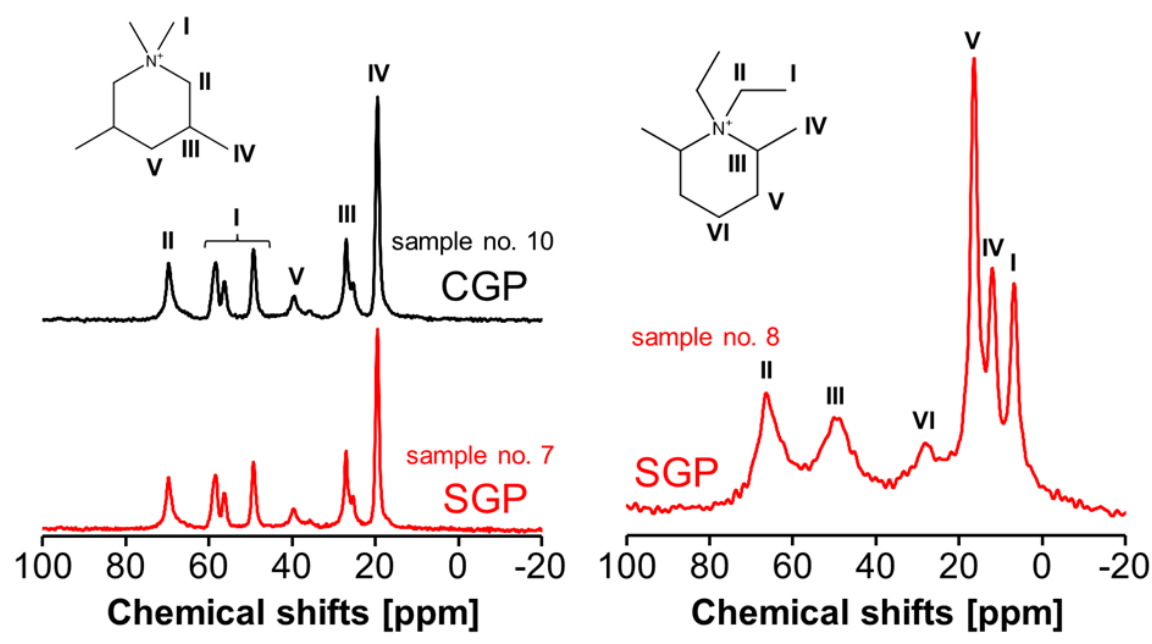

Figure S1. ${ }^{13} \mathrm{C}$ CP MAS NMR spectra of AEI zeolites obtained from amorphous starting materials in the presence of seed crystal (sample no. 7, 8 and 10). 

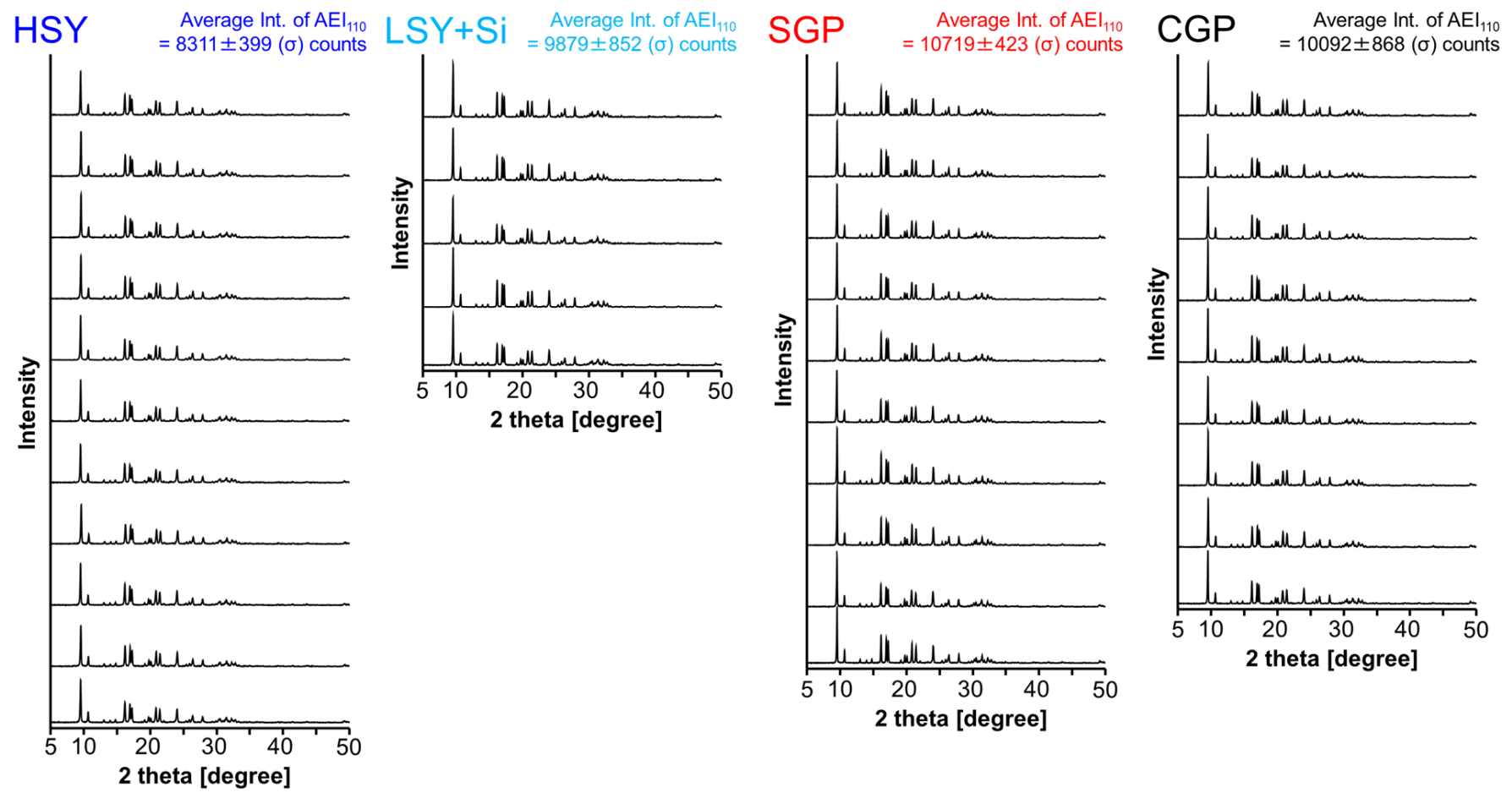

Figure S2. Repeated synthesis of AEI zeolites using DMDMP in the presence of seed crystal (synthesis condition are entry 1, 4, 7 and 10). The crystallinity and its standard deviations were calculated by using XRD peak intensity of AEI (110 reflection). 


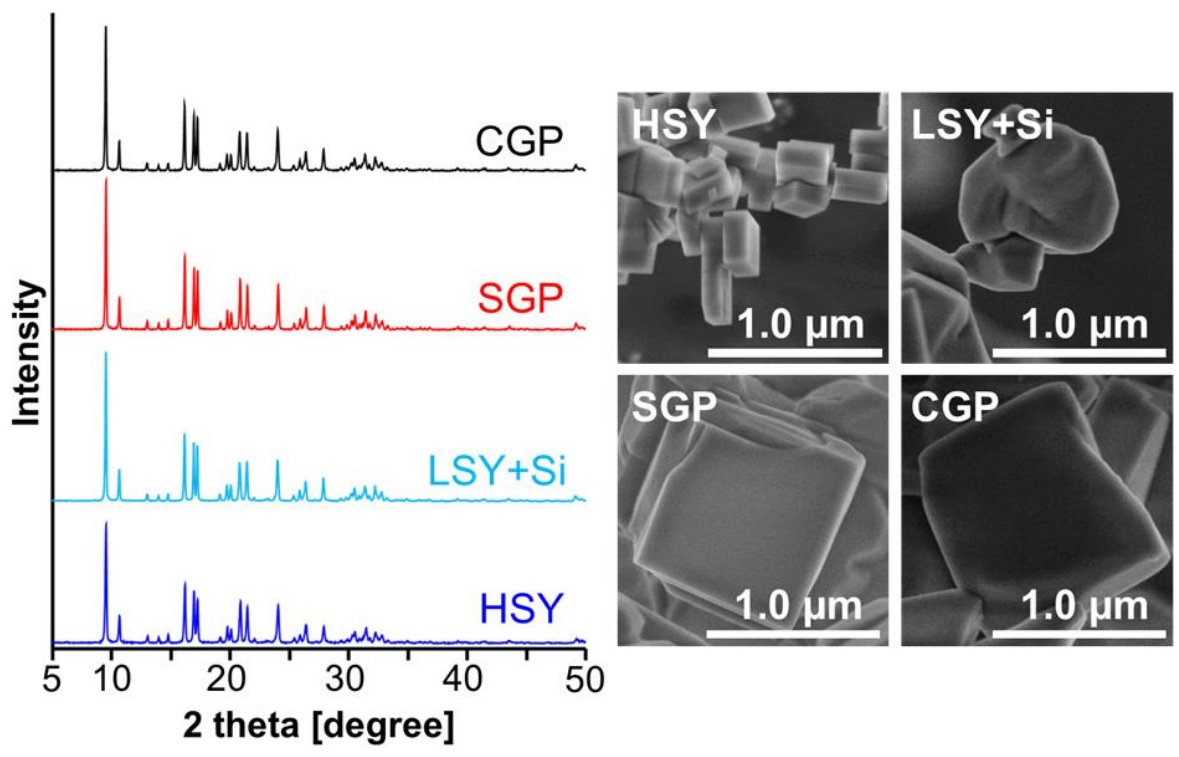

Figure S3. (left) XRD patterns and (right) SEM images of AEI zeolites obtained from various starting materials using DMDMP in the presence of seed crystal (samples no. 1, 4, 7, and 10). 


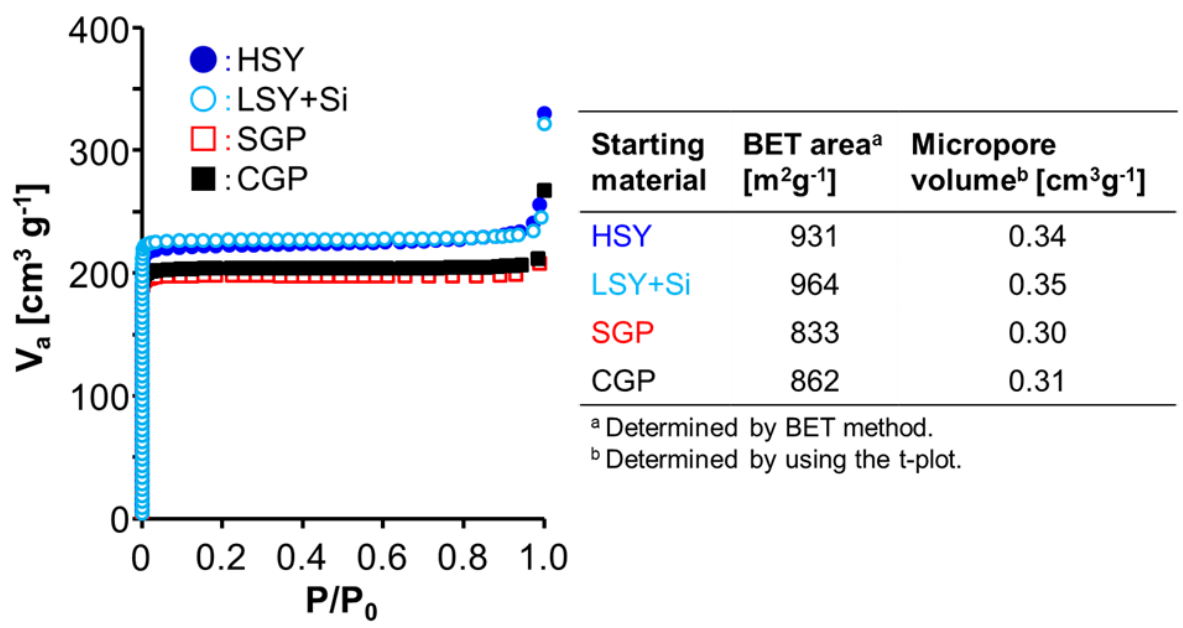

Figure S4. $\mathrm{N}_{2}$ adsorption isotherms and pore characteristics of AEI zeolites obtained from various starting materials using DMDMP in the presence of seed crystal (sample no. 1, 4, 7 and 10). 

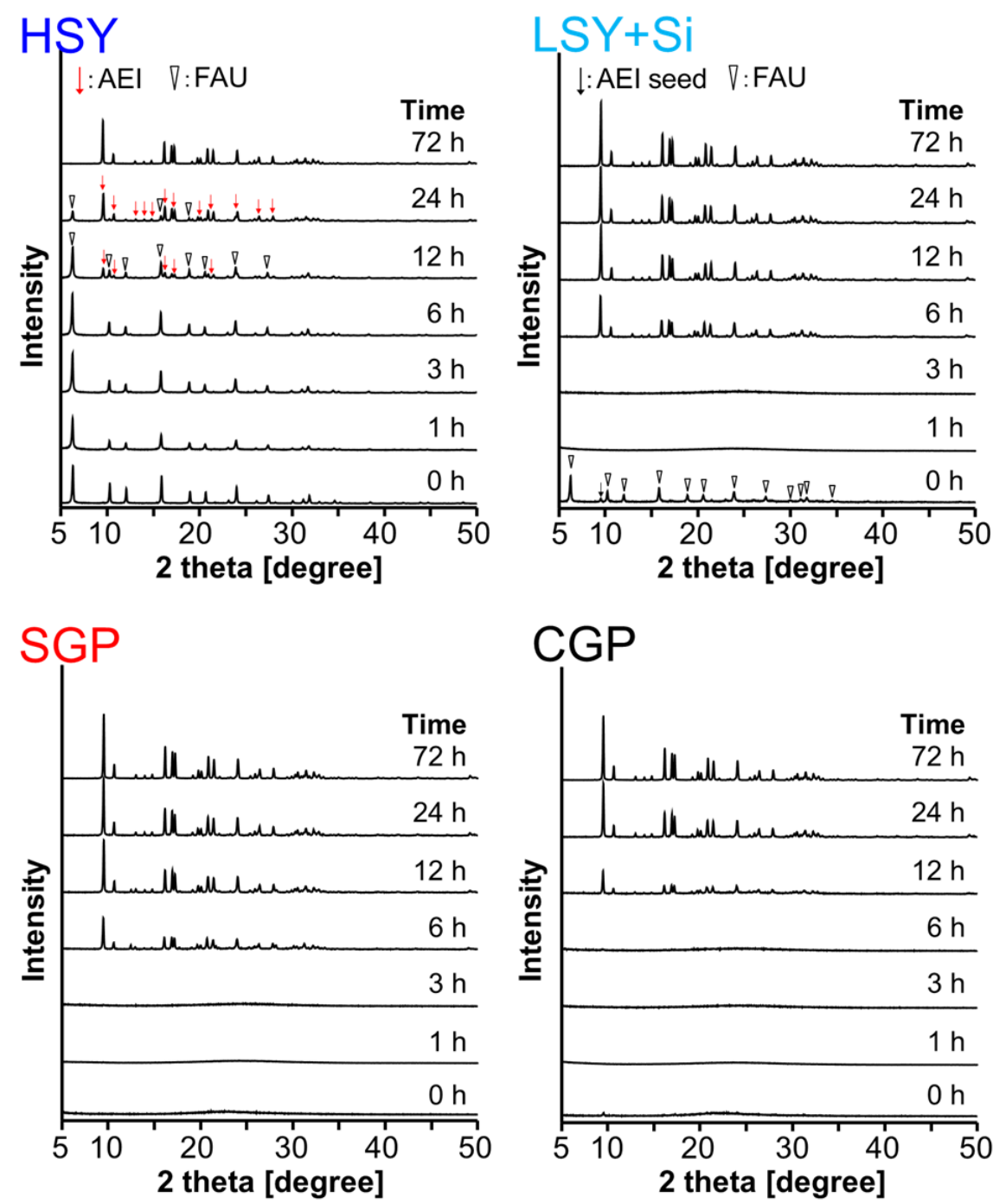

Figure S5 XRD patterns of products obtained from various starting materials using DMDMP in the presence of seed crystal with different hydrothermal treatment time. 

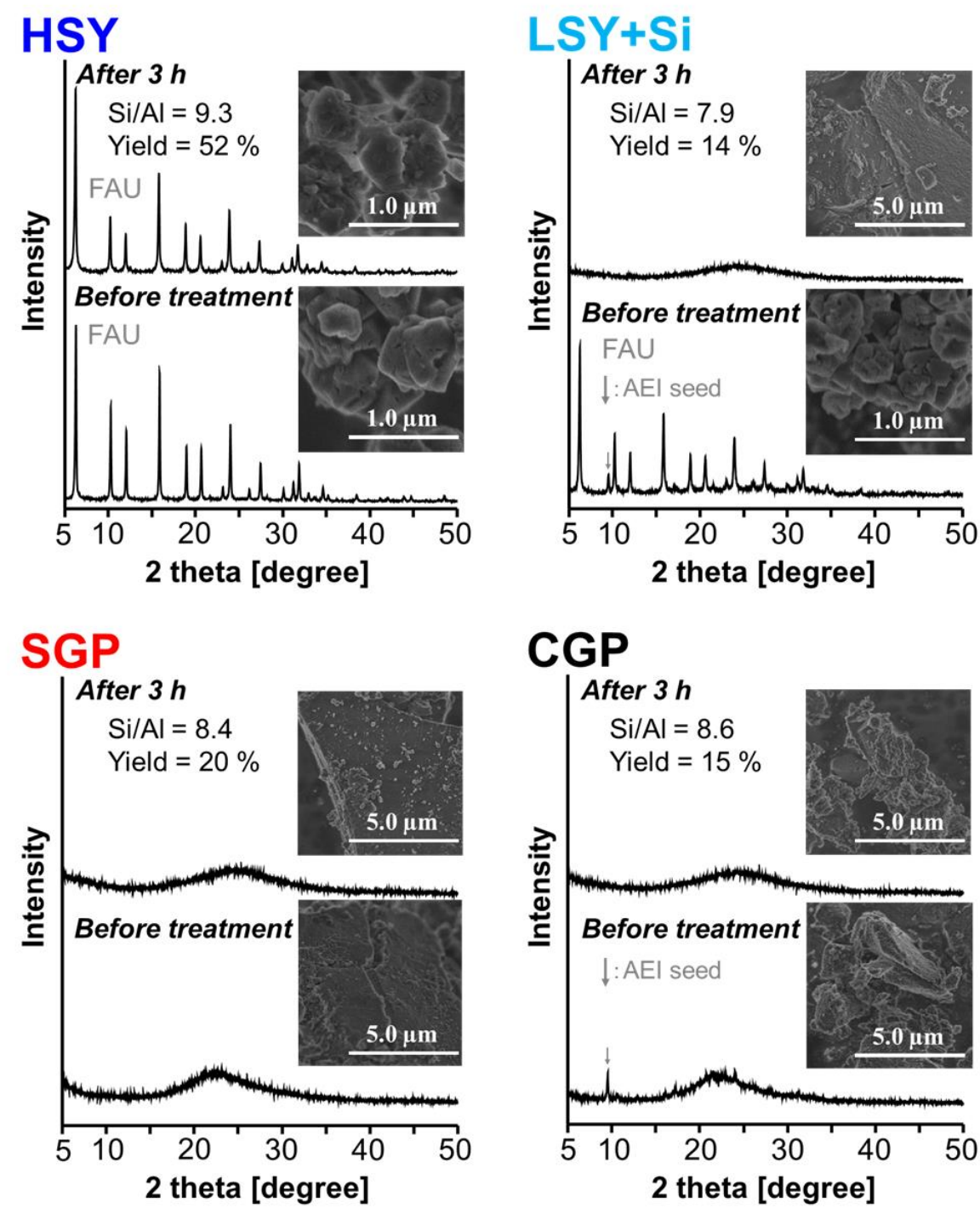

Figure S6. XRD patterns and SEM images of products obtained from various starting materials using DMDMP in the presence of seed crystal before and after $3 \mathrm{~h}$ of hydrothermal treatment: gray characters indicate the framework structure of zeolite obtained. 

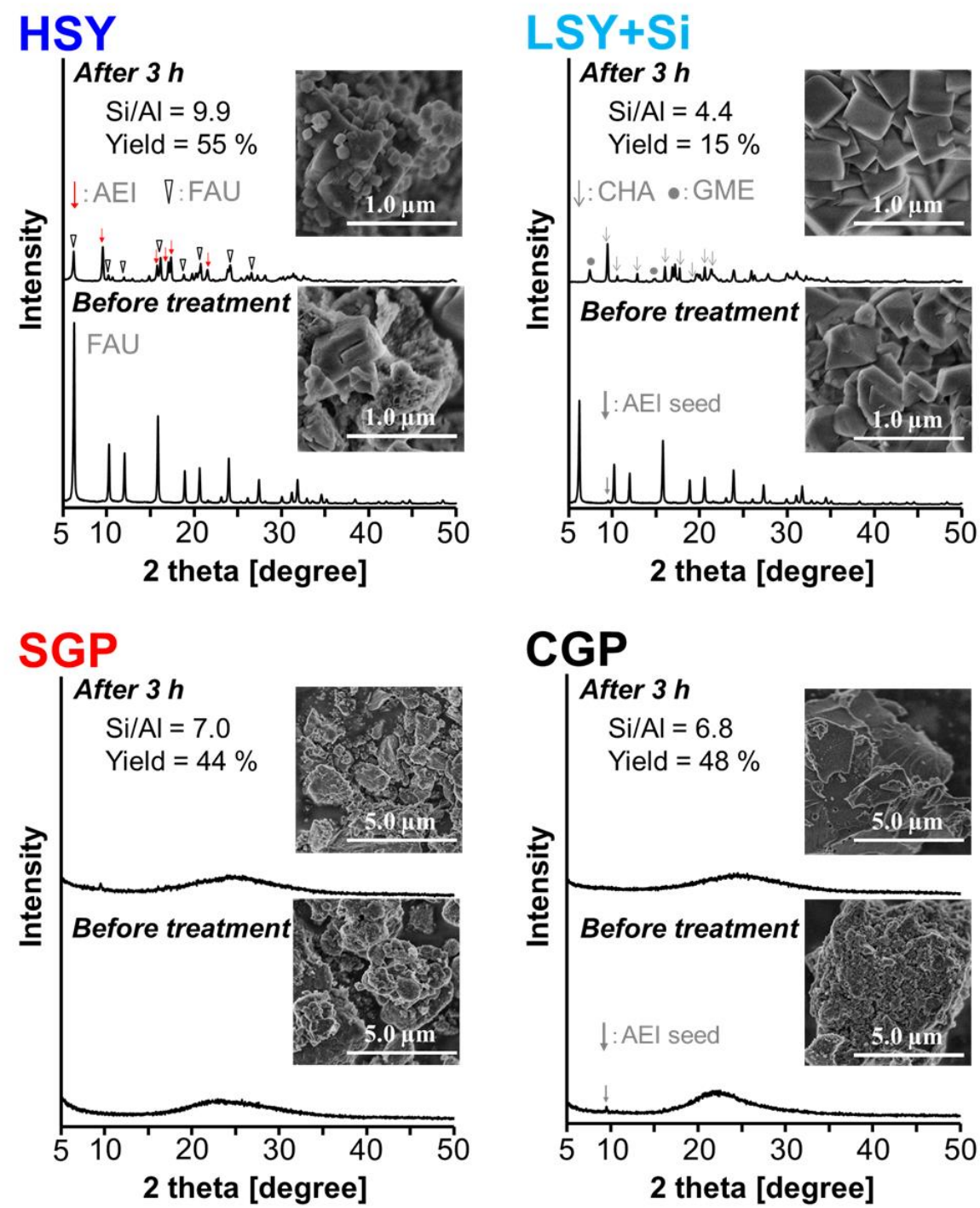

Figure S7. XRD patterns and SEM images of products obtained from various starting materials using DEDMP in the presence of seed crystal before and after $3 \mathrm{~h}$ of hydrothermal treatment. Gray characters indicate framework structure of zeolite obtained. 

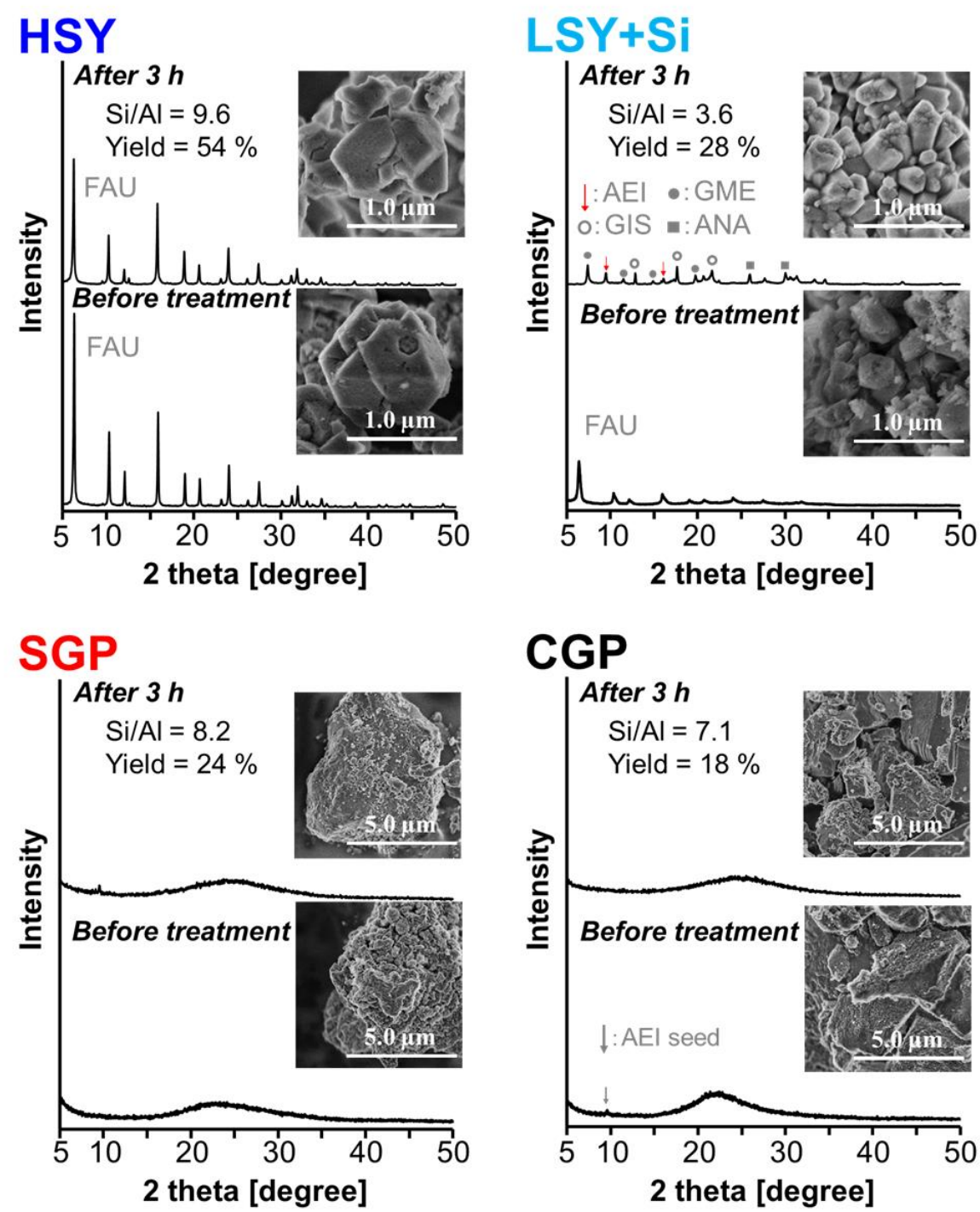

Figure S8. XRD patterns and SEM images of products obtained from various starting materials using TEP in the presence of seed crystal before and after $3 \mathrm{~h}$ of hydrothermal treatment. Gray characters indicate framework structure of zeolite obtained. 


\section{Before hydrothermal treatment}

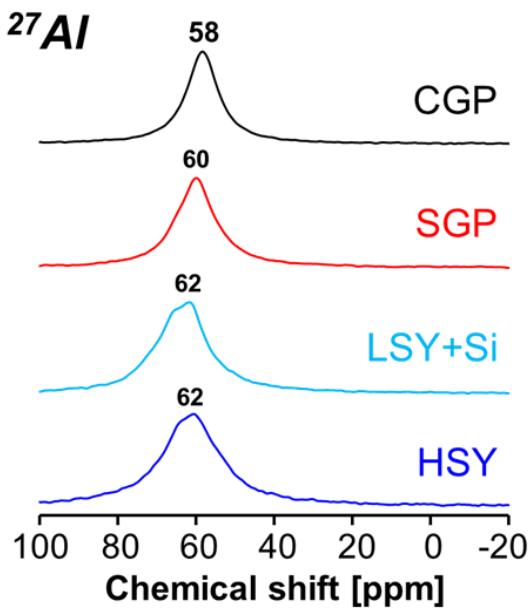

${ }^{29} \mathrm{Si}$
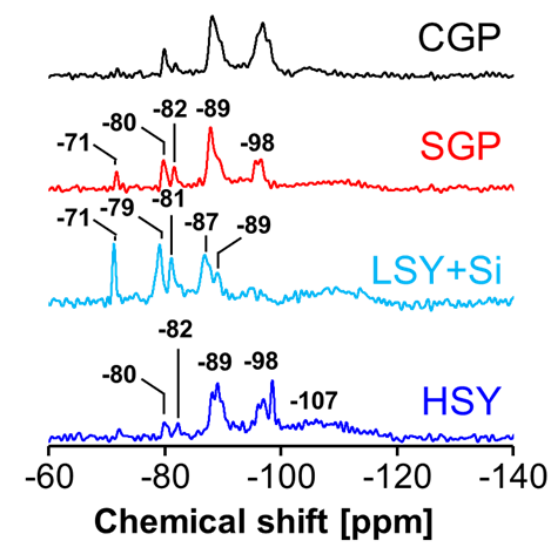

\section{After $3 \mathrm{~h}$ of hydrothermal treatment}

${ }^{27} \mathrm{Al}$

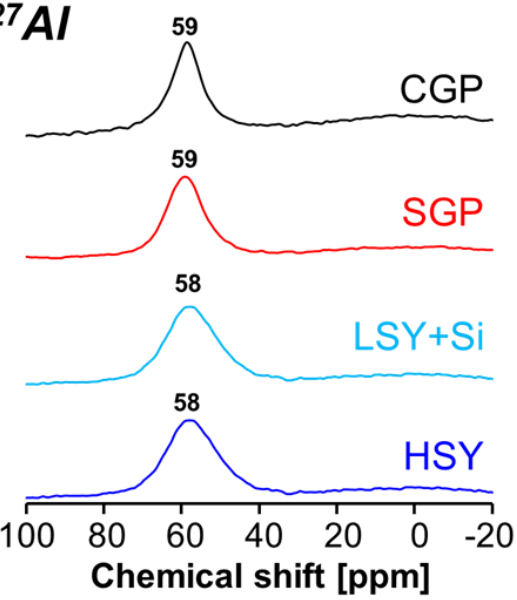

${ }^{29} \mathrm{Si}$
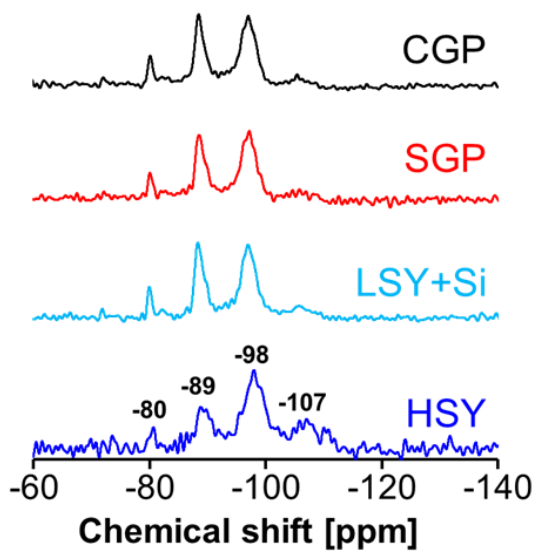

Figure S9. ${ }^{27} \mathrm{Al}$ and ${ }^{29} \mathrm{Si}$ NMR spectra of synthesis gel before and after $3 \mathrm{~h}$ of hydrothermal treatment prepared using various starting materials with DMDMP in the presence of seed crystal. 


\section{DEDMP}

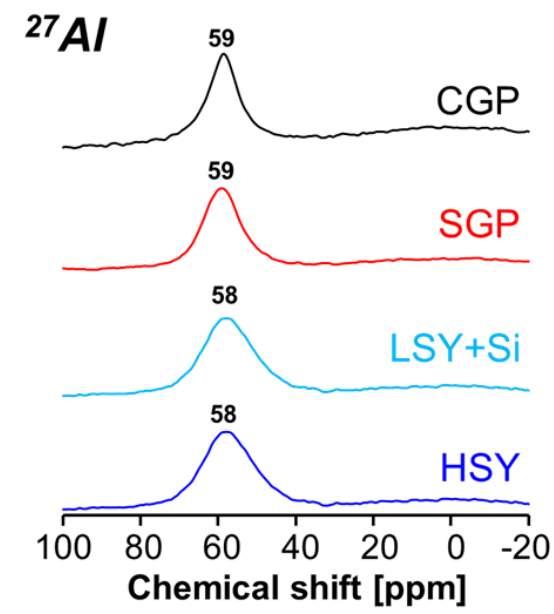

\section{TEP}

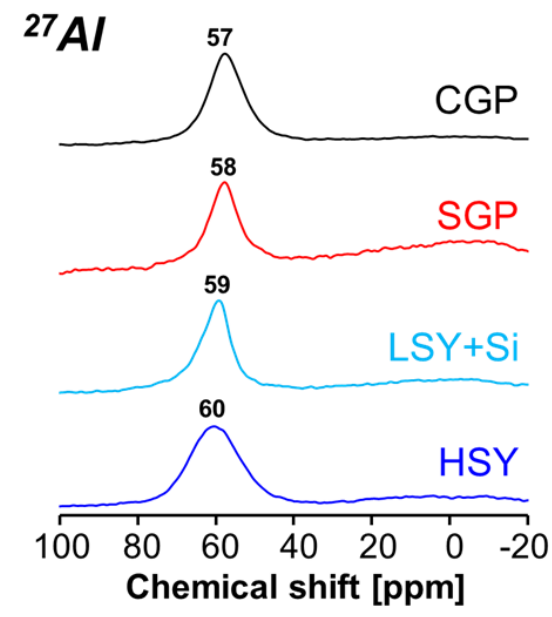

${ }^{29} \mathrm{Si}$

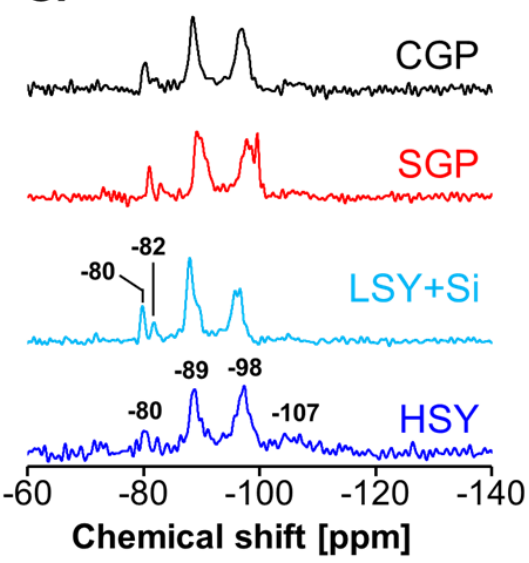

${ }^{29} \mathrm{Si}$
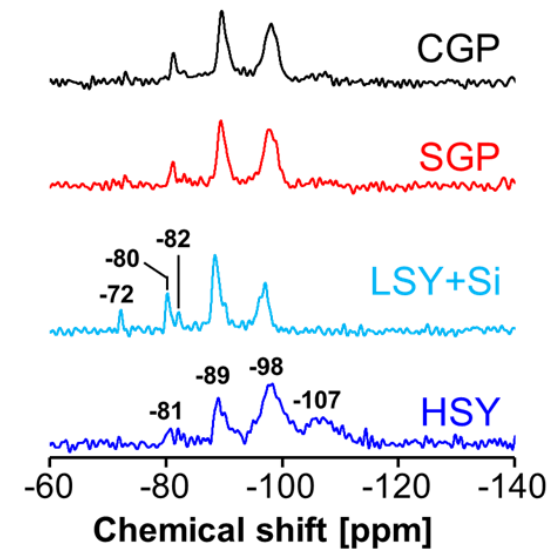

Figure S10. ${ }^{27} \mathrm{Al}$ and ${ }^{29} \mathrm{Si}$ NMR spectra of synthesis gel after $3 \mathrm{~h}$ of hydrothermal treatment prepared using various starting material and OSDAs in the presence of seed crystal. 


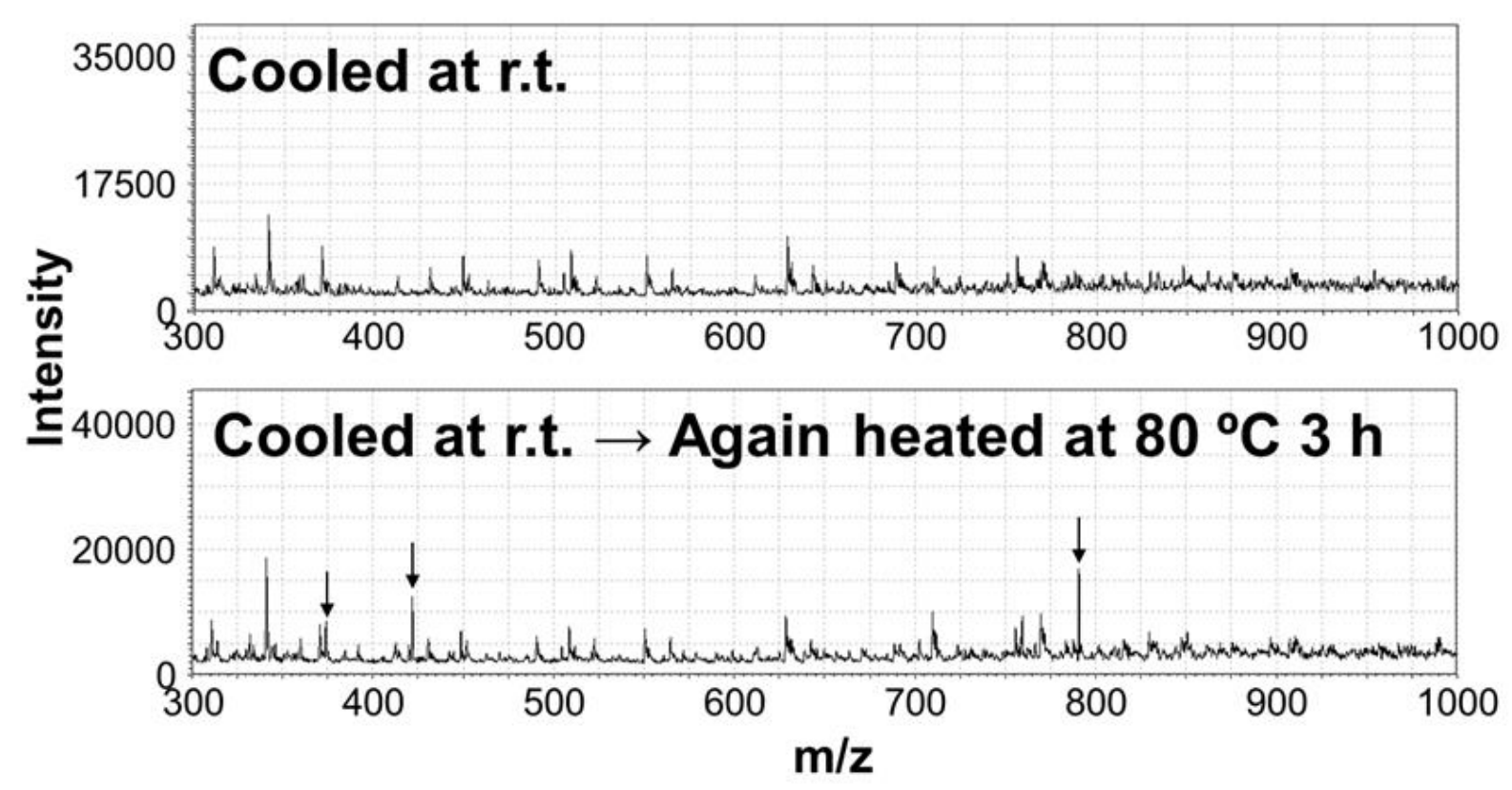

Figure S11. ESI-MS analysis $(\mathrm{m} / \mathrm{z}=300-1000)$ of cooled and again heated measurement for the liquid phase after $3 \mathrm{~h}$ of hydrothermal treatment of synthesis gel prepared using HSY and DMDMP in the presence of seed crystal. The black arrow indicates an unknown peak but they are not silicate species because of no isotope $[\mathrm{M}+1]^{-}$peaks may be some shock peak or contamination from the polypropylene vessel for heating treatment. 


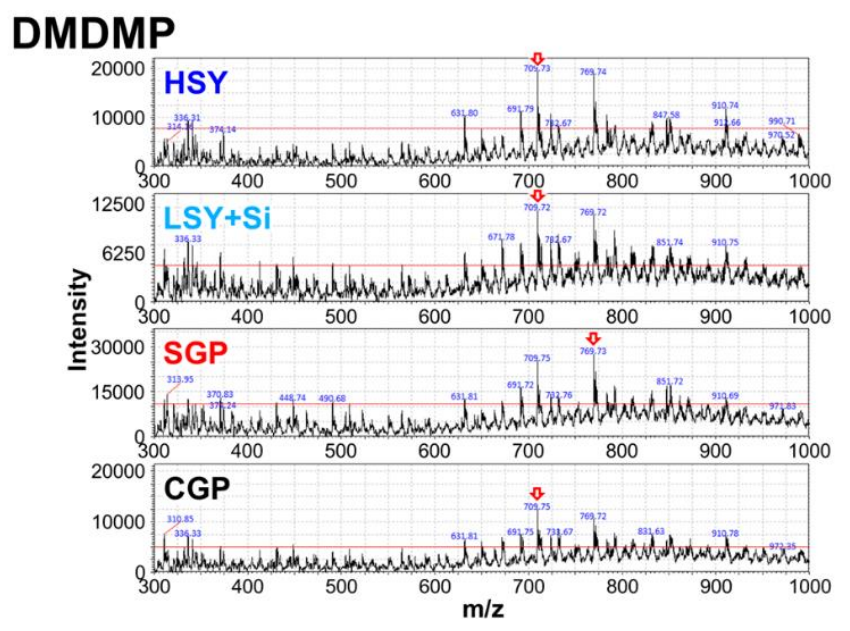

\section{DEDMP}

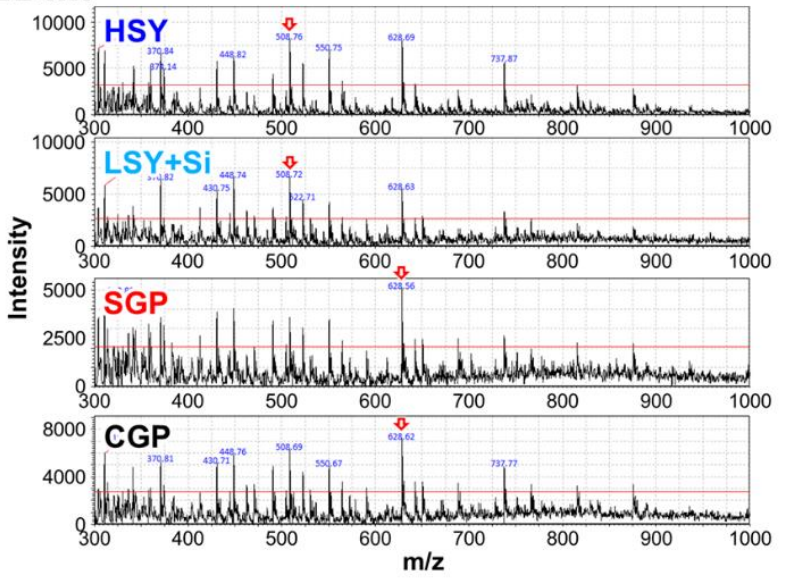

TEP

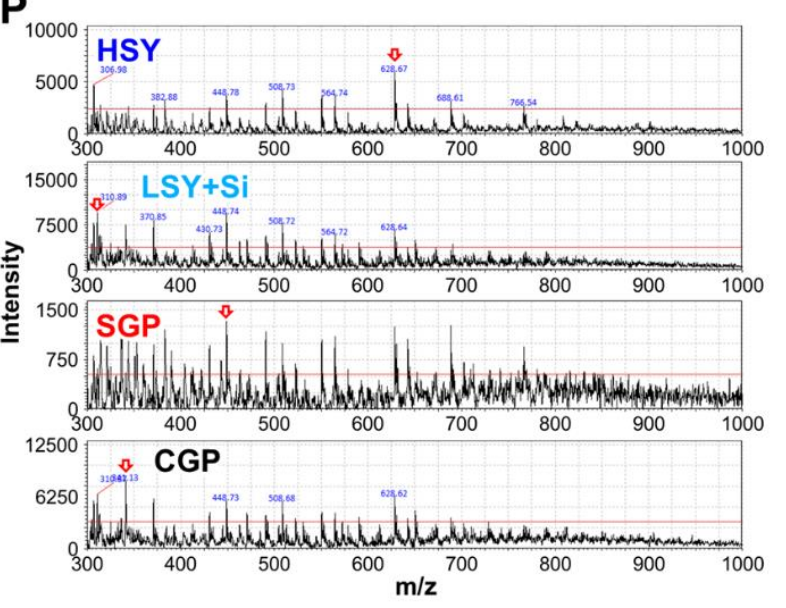

Figure S12. ESI-MS spectra $(\mathrm{m} / \mathrm{z}=300-1000)$ of the liquid phase after $3 \mathrm{~h}$ of hydrothermal treatment of synthesis gel prepared using various starting materials and OSDAs in the presence of seed crystal. 

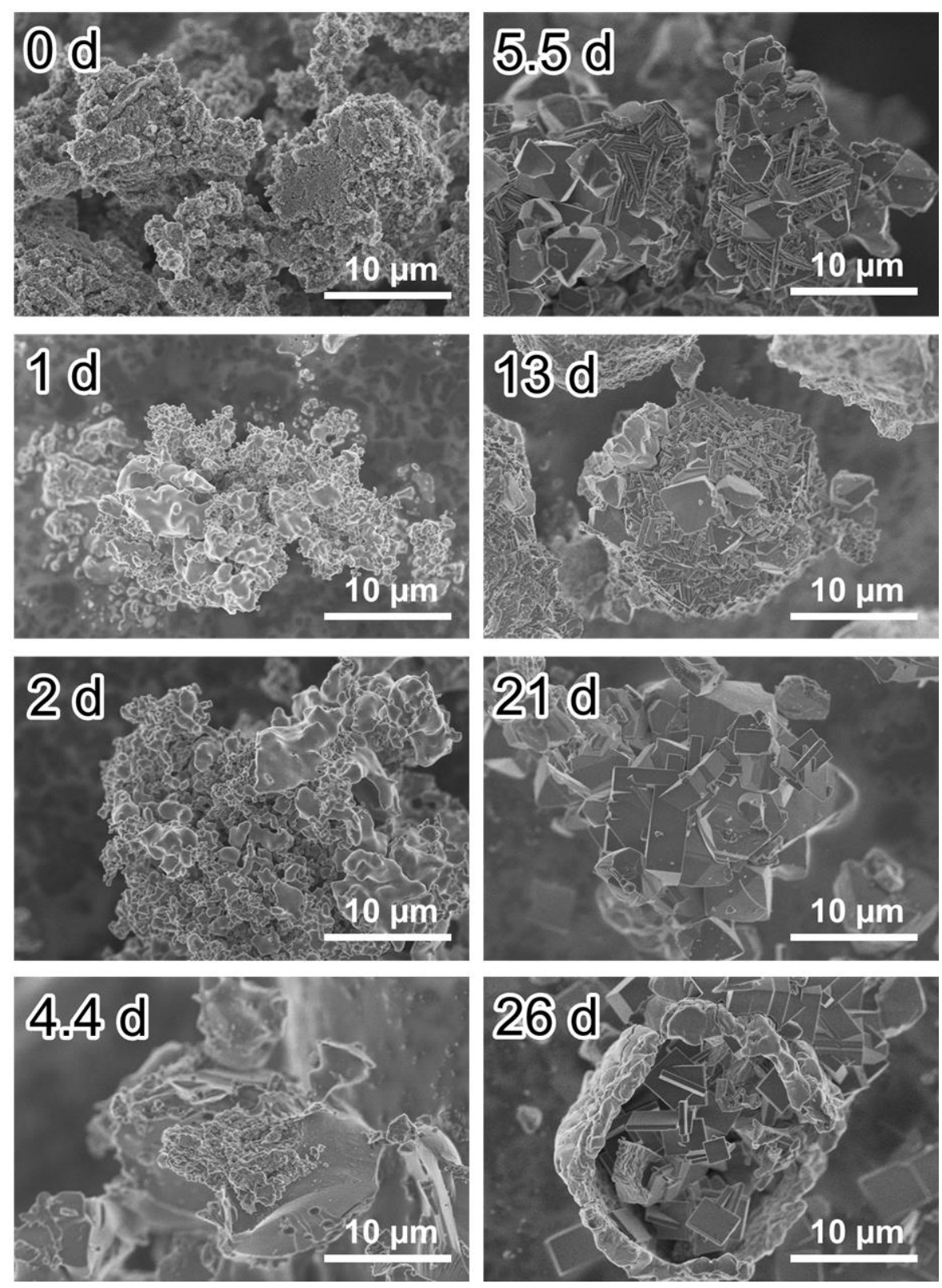

Figure S13. SEM images of solid products obtained from SGP gel using DMDMP in the absence of seed crystal (The gel composition is entry 14 in Table 4). 


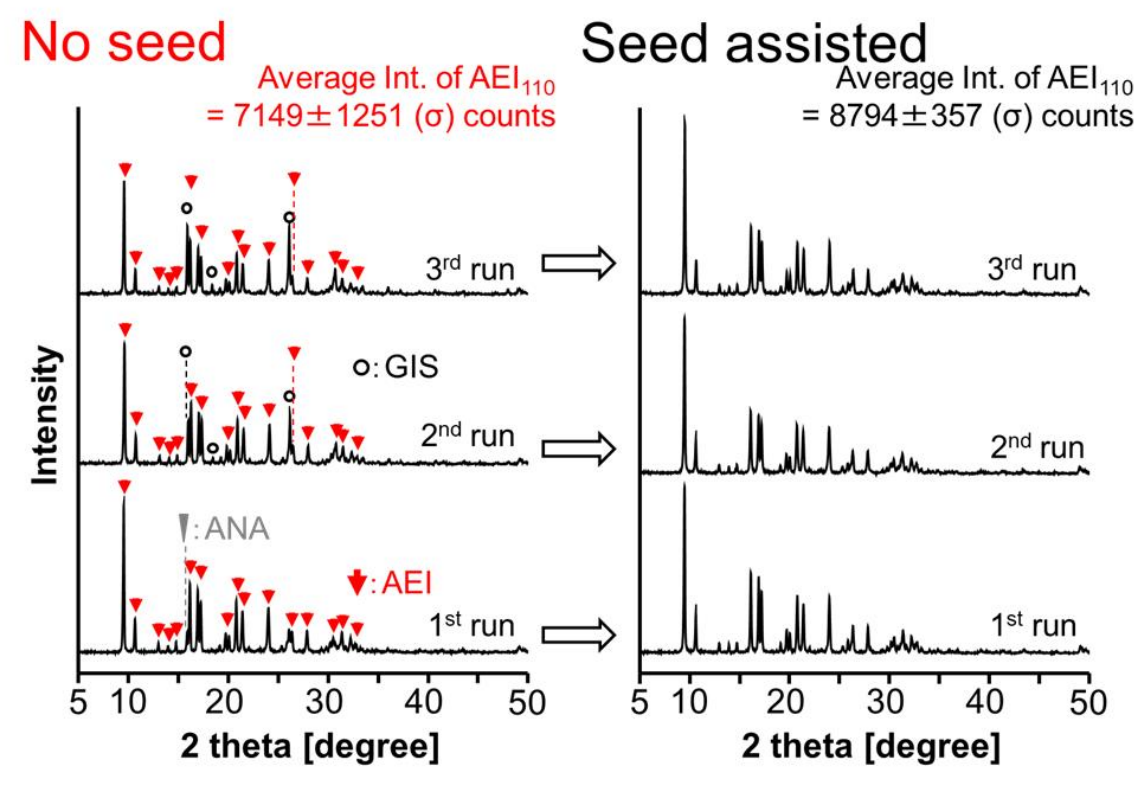

\section{Seed assisted}
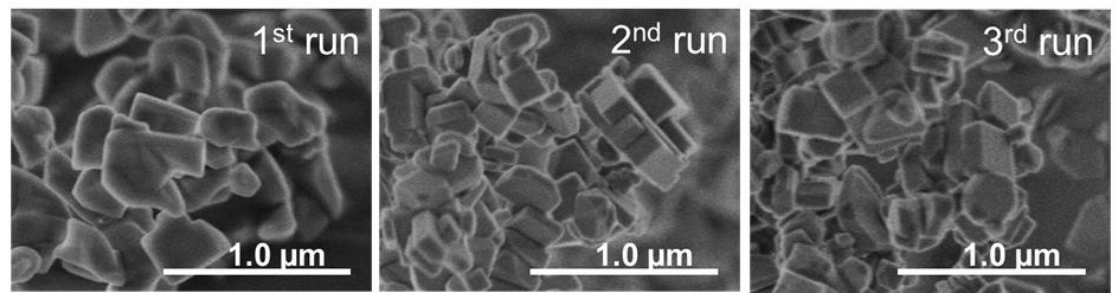

Figure S14. Confirmation of reproducibility for the AEI zeolite synthesis without seed crystal; (left top) XRD pattern of the samples obtained from repeated synthesis of entry 14 and (right top) XRD patterns and (bottom) SEM images of the samples obtained from repeated seed-assisted synthesis of entry 22 (AEI zeolites obtained in each runs were used as a seed crystal). The crystallinity and its standard deviations were calculated by using XRD peak intensity of AEI (110 reflection). 

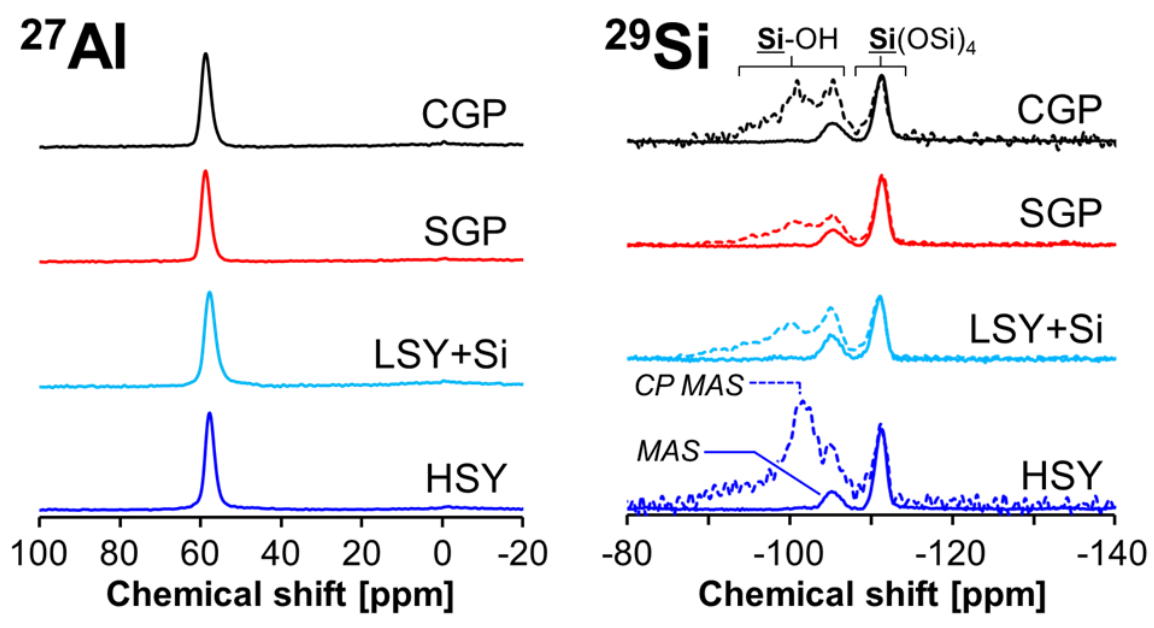

Figure S15. (left) ${ }^{27} \mathrm{Al}$ and (right) ${ }^{29} \mathrm{Si}(\mathrm{CP})$ MAS NMR spectra of AEI zeolites obtained from various starting materials using DMDMP in the presence of seed crystal (H-form, sample no. 1, 4, 7 and 10). 